\title{
Being Normal Weight but Feeling Overweight in Adolescence May Affect Weight Development into Young Adulthood-An 11-Year Followup: The HUNT Study, Norway
}

\author{
Koenraad Cuypers, ${ }^{1}$ Kirsti Kvaløy,, Grete Bratberg, ${ }^{1,2}$ Kristian Midthjell, ${ }^{1}$ \\ Jostein Holmen, ${ }^{1}$ and Turid Lingaas Holmen ${ }^{1}$ \\ ${ }^{1}$ HUNT Research Center, Department of Public Health and General Practice, Faculty of Medicine, \\ Norwegian University of Science and Technology, Forskningsveien 2, 7600 Levanger, Norway \\ ${ }^{2}$ Research Department, Levanger Hospital, Nord-Trøndelag Health Trust, Nord-Trøndelag, Norway
}

Correspondence should be addressed to Koenraad Cuypers, koenraad.cuypers@ntnu.no

Received 28 September 2011; Revised 9 February 2012; Accepted 15 March 2012

Academic Editor: Simone Lemieux

Copyright ( $) 2012$ Koenraad Cuypers et al. This is an open access article distributed under the Creative Commons Attribution License, which permits unrestricted use, distribution, and reproduction in any medium, provided the original work is properly cited.

Objectives. To explore if self-perceived overweight in normal weight adolescents influence their weight development into young adulthood and if so, whether physical activity moderates this association. Methods. A longitudinal study of 1196 normal weight adolescents (13-19 yrs) who were followed up as young adults (24-30 yrs) in the HUNT study. Lifestyle and health issues were assessed employing questionnaires, and standardized anthropometric measurements were taken. Chi square calculations and regression analyses were performed to investigate the associations between self-perceived overweight and change in BMI or waist circumference (WC) adjusted for age, age squared, sex, and other relevant cofactors. Results. Adolescents, defined as being normal weight, but who perceived themselves as overweight had a larger weight gain into young adulthood than adolescents who perceived themselves as normal weight (difference in BMI: 0.66 units [CI95\%: 0.1, 1.2] and in WC: $3.46 \mathrm{~cm}$ [CI95\%: 1.8, 5.1]). Level of physical activity was not found to moderate this association. Conclusions. This study reveals that self-perceived overweight during adolescence may affect development of weight from adolescence into young adulthood. This highlights the importance of also focusing on body image in public health interventions against obesity, favouring a "healthy" body weight taking into account natural differences in body shapes.

\section{Introduction}

Overweight and obesity are increasing in many parts of the world and are one of the major risk factors causing health problems [1]. Preventing adolescents from becoming obese adults is important for their future health and may reduce health-care costs [2]. Weight control and ideal body shape have evolved to be a main focus not only in health promotion policies but also in commercial businesses. The public is overwhelmed with advertisements and information, resulting in weight norms which are hard to reach for many people and in slimming pressure [3]. Especially girls' psychological wellbeing might be disadvantaged by weight misperception and the wish to lose weight [4].
Paradoxically, as the social pressure for thinness and the associated stigmatization of obesity have increased [5], so has the prevalence of obesity [6] and thus, the discrepancy between desirable body weight and actual body weight has increased [7]. This may easily cause distress $[4,8]$ and perceived psychosocial stress has, in turn, been found to increase adiposity [9-11], especially central obesity [12].

Adolescence is a period in life when risk behaviors may be established enhancing the risk for diseases in later adulthood [13]. As youth in modern society are overwhelmed by public health messages and commercial information from media, often negatively focused on obesity, this may affect young people's perception of weight norms, particularly in this vulnerable period of life. Weight misperception, especially 
self-perceived overweight and slimming behaviors, seems to be highly prevalent among adolescents $[8,14]$.

Previous studies have mainly focused on obese subjects when documenting that dieting [15] and worries about weight [9] may have a negative impact on health. In this way, body image has been reported to mediate the relationship between obesity and psychological distress [7] and mortality has been associated with intention to loose weight in overweight adults [15]. In adolescents the feeling of overweight, rather than being overweight has been suggested to be associated with psychological wellbeing [11]. Further, body image dissatisfaction has been reported to contribute to suicidal ideation [10] and depression [16]. In a crosssectional study Perkins et al. [17] noted that adolescents who misperceived peer weight norms toward overweight had a greater risk for being overweight.

Previous studies have focused on several health outcomes in obese people but have not been concerned with the effect that self-perceived overweight in normal weight adolescents might have on subsequent weight gain into adulthood in a longitudinal design. Lessening the psychosocial pressure by improving the weight perception in youth may be an important focus in prevention strategies for counteracting the development of overweight.

Thus, the aims in this longitudinal study were to investigate whether self-perceived overweight in normal weight adolescents might have an impact on the development of their weight into young adulthood and if so, whether physical activity moderated this association.

\section{Methods}

2.1. Study Population. HUNT, the Health Study of NordTrøndelag, is a large-population-based study carried out three times during the last 25 years in the county of NordTrøndelag, Norway (http://www.ntnu.no/hunt/). NordTrøndelag County (130 000 inhabitants) has a homogenous population and has a geographical, demographical, and occupational structure fairly representative of the whole of Norway, though lacking large cities $[18,19]$. The average income and mean educational level are slightly lower than the national average. The socioeconomic inequality in mortality in the region is at the national level [20].

Young-HUNT is the adolescent part (13-19 years) of HUNT. The Young-HUNT 1 survey was carried out in 1995-97 as part of HUNT2. The follow-up study presented in this paper includes participants in Young-HUNT1 who also participated as young adults (24-30 years) in HUNT 3 carried out in 2006-2008.

All students in junior high and senior high schools were invited to participate in Young-HUNT1, and 8408 (83\%) completed both a comprehensive questionnaire about life style, health, and quality of life and underwent a clinical examination including anthropometric measures during school hours. A total of 5616 adolescents had a BMI within the normal range according to the International Obesity Task Force's (IOTF) criteria for adolescents defined by Cole et al. [21] and reported no psychological or physical dysfunctions that affected their daily activities. The 59 participants who reported to be pregnant at followup were excluded. Finally, 1196 adolescents who participated in both Young-HUNT1 (aged 13-19 yrs) and as young adults (24-30 yrs) in HUNT 3 were included in the present study (Figure 1).

In HUNT3, data was also collected by comprehensive self-administered questionnaires which included questions on physical and mental health, somatic complaints, and lifestyle. Anthropometric measures were obtained by specially trained nurses using the same standardized protocols as in Young-HUNT1. In both Young-HUNT1 (baseline) and HUNT3 (followup) height and weight were measured to the nearest centimetre, respectively to the nearest half kilogram with light clothes, without shoes, jacket, or outdoor garments. Waist circumference (WC) was measured to the nearest centimetre, applying a nonstretchable band horizontally at the umbilical level after the participants emptied their lungs or midway between the last rib and the iliac cristae if the latter was largest [19].

Predictors at baseline were used to study weight gain, in BMI units $\left(\mathrm{kg} / \mathrm{m}^{2}\right)$ and centimetres (WC), at followup.

2.2. Variables at Baseline: Young-HUNT1 (1995-97). Selfperceived overweight was defined as feeling "Chubby" or "Very fat" to the question "How do you consider yourself?" The adolescents had to tick off one of the five possible answer categories: very fat, chubby, about the same as others, thin, very thin.

Physical activity was implemented as a continuous variable and was defined as: "outside of school, performing sports or exercise to the point of heavily breathing and/or sweating". We assigned values 1 through 8 to the response options: everyday, 4-6 days a week, 2-3 days a week; 1 day a week; not every week but at least once every two weeks; not every 14th day but at least once a month; less than once a month; never. This physical activity question, also used in the World Health Organization Health Behaviour in Schoolchildren (WHO HBSC) Survey Questionnaire [22], has previously been validated in the Young-HUNT population [22]. Sedentary behaviour is reported to be a risk factor for weight gain in youth [23] and was adjusted for in the analyses. Reading a book, playing or listening to music, watching TV, and doing homework were included in the variable. Social activities were also adjusted for, as these activities have been suggested to be important in the onset and spread of obesity [24]. The following social activities were included: visiting someone, receiving visit, being out with friends, and being at a meeting. To assess sedentary behaviour or social activities we used the following question: "Think back over the last week, the last 7 days. If you did any of the sedentary or social cultural activities listed above, tick off for about how many times you did this." Not once, once, 2 or 3 times, 4 times or more. For each activity, each response alternative was quantified with 1 to 4 and we computed two indices by summing the score for each question, one index for sedentary behaviour and one index for the social activities. These two indices (4-16) were introduced in the models as continuous variables. 


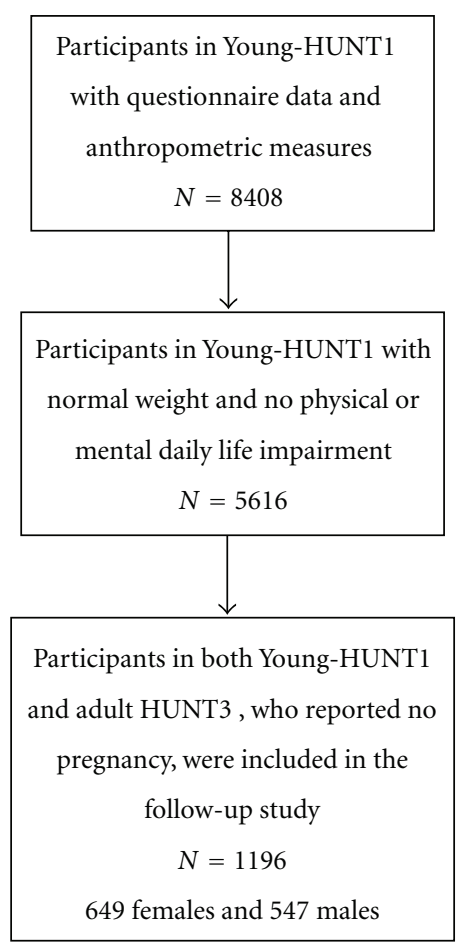

Figure 1: Sampling flow chart.

Eating habits are indicated as being predictors of weight gain from adolescence to adulthood [25]. To assess eating habits the following three questions in Young-HUNT1 were selected and used as continuous variables: "How often do you usually eat breakfast?" Answer categories were: every day, 46 days a week, 1-3 days a week, seldom or never and "How often do you do you eat" any of these items: "Vegetables" or "Fruits" each with five answer categories: more than once a day, once a day, every week but not every day, seldom, never.

2.3. Variables Used at Followup, HUNT3 (2006-08). Weight status in the followup population was defined, according to $\mathrm{WHO}$ recommendations, using $\mathrm{BMI} \geq 25 \mathrm{~kg} / \mathrm{m}^{2}$ as overweight and BMI $\geq 30 \mathrm{~kg} / \mathrm{m}^{2}$ as obesity [26]. Central overweight was defined as $\mathrm{WC} \geq 80 \mathrm{~cm}$ for females and $\mathrm{WC} \geq 94 \mathrm{~cm}$ for males $[26,27]$. Central obesity was defined as $\mathrm{WC} \geq 88 \mathrm{~cm}$ or $\geq 102 \mathrm{~cm}$, for females and males, respectively $[26,28]$.

The physical activity index was the product of frequency, intensity and duration scales of physical activity from the adult questionnaire [29]. A range from 0 through 15 was used as a continuous variable in the regression models.

Socioeconomic status (SES) was measured at followup in HUNT3 (2006-08) reclassifying the first digit in the Norwegian occupation classification (STYRK) into an approximation to the Erikson Goldthorpe Portocarero social class scheme (higher-grade professionals, lower-grade professionals, nonmanual employees, small proprietors, artisans and farmers, lower grade technicians, and unskilled workers) [30].

\section{Statistics}

Descriptive statistics were used to compare data for the Young-HUNT1 participants, included in the present study, with the total Young-HUNT1 population from which the final study sample was selected.

Separate independent $t$-tests were used to test ageand gender-specific differences in mean anthropometric measures at both baseline and followup comparing adolescents with and without self-perceived overweight and, in addition, comparing those who became overweight or obese at followup with those who did not.

Likelihood ratio Chi square were calculated from $2 \times 2$ contingency tables to determine the differences in prevalence of overweight and obesity status at followup between those reporting self-perceived overweight and those who reported no self-perceived overweight at baseline.

To deal with the possible differences in baseline BMI between the group who perceived themselves as overweight and the group who perceived themselves as about normal weight, we investigated the association between selfperceived overweight and weight gain from adolescence into young adulthood. Weight gain, that is, change in overall adiposity (delta BMI) was calculated by subtracting BMI at baseline from BMI at followup. The same calculation was done in regard to change in central adiposity (delta WC). Both BMI and WC were employed because they may reflect different aspects of adiposity.

In separate models, adjusted linear regression was used to examine the relationships between self-perceived overweight at baseline and weight gain (delta-BMI and delta-WC) as outcome variables. With an age span from 13 to 19 years at baseline it was expected that the youngest girls and boys should have a larger weight gain due to normal growth compared to the oldest participants and that the relationship between age and body mass was not linear. Since age was such a strong confounder we adjusted for age and age square. Additionally, we also adjusted for sex in the first model (model I).

In the second linear regression model the association was also simultaneously adjusted for the following factors at baseline: physical activity, eating habits (i.e., frequency of eating breakfast, fruits, or vegetables), social activities, sedentary behaviour, and at followup: socioeconomic status (SES) and physical activity.

Interaction between self-perceived overweight and sex was tested by introducing a cross-product term (selfperceived overweight $*$ sex) in the second model. Also possible interactions between self-perceived overweight and physical activity were tested in additional models by introducing respectively a cross-product term (self-perceived overweight $*$ physical activity) in one model implying physical activity at baseline and in another model physical activity at followup.

\section{Ethics}

All participants and guardians of adolescents younger than 16 years signed an informed consent to participation and 
TABLE 1: Comparison of baseline and follow-up characteristics between adolescents who perceived themselves as overweight (74\% girls, $26 \%$ boys), despite not being overweight versus those who did not perceive themselves as overweight (50.6\% girls, $49.4 \%$ boys). ( $n=1196)$.

\begin{tabular}{|c|c|c|c|c|c|c|c|c|c|c|}
\hline & \multicolumn{4}{|c|}{ Baseline characteristics } & \multicolumn{6}{|c|}{ Follow-up characteristics } \\
\hline & \multicolumn{2}{|c|}{$\begin{array}{l}\text { Self-perceived } \\
\text { overweight }\end{array}$} & \multicolumn{2}{|c|}{$\begin{array}{c}\text { No self-perceived } \\
\text { overweight }\end{array}$} & \multirow[t]{2}{*}{$P$ value } & \multicolumn{2}{|c|}{$\begin{array}{c}\text { Self-perceived } \\
\text { overweight }\end{array}$} & \multicolumn{2}{|c|}{$\begin{array}{c}\text { No self-perceived } \\
\text { overweight }\end{array}$} & \multirow[t]{2}{*}{$P$ value } \\
\hline & & $\mathrm{SD}$ & & SD & & & $\mathrm{SD}$ & & $\mathrm{SD}$ & \\
\hline BMI & 21.8 & 1.7 & 20.4 & 1.7 & N.S. & 26.5 & 3.8 & 24.4 & 3.3 & $<0.001$ \\
\hline Height & 166.9 & 8.1 & 169.9 & 8.3 & N.S. & 170.3 & 8.0 & 173.7 & 9.1 & $<0.001$ \\
\hline Weight & 60.8 & 6.9 & 59.0 & 7.1 & N.S. & 77.0 & 13.3 & 74.0 & 13.0 & $<0.001$ \\
\hline WC & 71.9 & 5.5 & 70.0 & 5.9 & N.S. & 90.7 & 11.3 & 85.5 & 10.5 & 0.005 \\
\hline Age & 15.9 & 1.8 & 15.9 & 1.8 & N.S. & 27.3 & 1.9 & 27.2 & 1.9 & N.S. \\
\hline
\end{tabular}

Baseline BMI, height, weight, and WC are age adjusted.

BMI: body mass index in $\mathrm{kg} / \mathrm{m}^{2}$ and WC (waist circumference) in centimetres.

N.S.: not significant.

TABLE 2: The percentages of the normal weight adolescents (baseline, $n=1196$ ) who became overweight or obese in young adulthood (followup). Adolescents who perceived themselves as overweight (self-perceived overweight) were compared to those who perceived themselves as normal weight.

\begin{tabular}{|c|c|c|c|c|c|c|c|}
\hline & & \multicolumn{2}{|c|}{ Overweight at followup } & \multicolumn{4}{|c|}{ Obese at followup } \\
\hline & & $\begin{array}{c}\text { Self- } \\
\text { perceived } \\
\text { overweight }\end{array}$ & $\begin{array}{c}\text { No self- } \\
\text { perceived } \\
\text { overweight }\end{array}$ & $P$ value & $\begin{array}{c}\text { Self- } \\
\text { perceived } \\
\text { overweight }\end{array}$ & $\begin{array}{c}\text { No self- } \\
\text { perceived } \\
\text { overweight }\end{array}$ & $P$ value \\
\hline \multirow{2}{*}{ Girls } & BMI (\%) & 59 & 31 & $<0.001$ & 16 & 6 & $<0.001$ \\
\hline & WC (\%) & 78 & 55 & $<0.001$ & 51 & 31 & $<0.001$ \\
\hline \multirow{2}{*}{ Boys } & BMI (\%) & 63 & 48 & $<0.05$ & 23 & 10 & $<0.001$ \\
\hline & WC (\%) & 55 & 29 & $<0.001$ & 37 & 10 & $<0.001$ \\
\hline
\end{tabular}

BMI: overweight BMI $\geq 25 \mathrm{~kg} / \mathrm{m}^{2}$, obese BMI $\geq 30 \mathrm{~kg} / \mathrm{m}^{2}$. WC: overweight WC $\geq 80 \mathrm{~cm}$ and $94 \mathrm{~cm}$, WC: obese WC $\geq 88 \mathrm{~cm}$ and $\geq 102 \mathrm{~cm}$, respectively, in female and male adults.

Adolescents classified as normal weight who reported psychological or physical dysfunctions and those who reported pregnancy at followup were excluded.

use of data in research. Participation in the HUNT study was voluntary and approved by the Norwegian Data Inspectorate, the Directorate of Health and recommended by the Regional Committee for Medical Research Ethics, who also approved the present study.

\section{Results}

Totally, 649 girls and 547 boys participated in both YoungHUNT1 (baseline) and HUNT3 (followup) and met the inclusion criteria of having normal weight, not being pregnant, and without mental or physical impairment at baseline. Mean age at baseline was 15.9 years (SD: 1.8) both in girls and boys and mean BMI was $20.7 \mathrm{~kg} / \mathrm{m}^{2}$ (SD: 1.9) in girls and $20.4 \mathrm{~kg} / \mathrm{m}^{2}$ (SD: 1.8 ) in boys. More girls (22\%) than boys $(9 \%)$ reported self-perceived overweight. These values were not significantly different in those who participated in Young-HUNT1 and met the inclusion criteria but did not participate at followup (HUNT3) (data not shown). Mean age at followup was 27.2 years (SD: 1.9) in females and 27.1 (SD: 1.9 ) in males and mean BMI was $24.4 \mathrm{~kg} / \mathrm{m}^{2}$ (SD: 3.7 ) in females and $25.3 \mathrm{~kg} / \mathrm{m}^{2}$ (SD: 3.1 ) in males.

Using $t$-tests adjusted for age, no significant differences were found between the baseline characteristics of the normal weight adolescents perceiving themselves as overweight compared to those not perceiving themselves as overweight
(Table 1). However, the differences between the follow-up characteristics were statistically different.

About half of the adolescents remained normal weight $\left(18.5 \leq \mathrm{BMI}<25 \mathrm{~kg} / \mathrm{m}^{2}\right)$ as young adults $(56 \%$ girls and $49 \%$ boys) while $30 \%$ of girls and $41 \%$ of boys became overweight and $8 \%$ of girls and $9 \%$ of boys became obese. The remaining percentages in girls and boys were classified as underweight and were as such not focused on in this paper. Using WC, slightly more girls (28\%) compared to boys $(21 \%)$ were defined as overweight, and substantially more girls $(34 \%)$ than boys $(9 \%)$ were defined as obese at followup.

At followup, overweight and obesity were more common among girls and boys who perceived themselves as overweight at baseline compared to those who did not perceive themselves as overweight. Adjusting for age did not change the prevalence data substantially (Table 2).

In the linear regression models, adjusted for age, age square and for sex, self-perceived overweight was significantly associated with weight gain into young adulthood. During the 11 years follow-up period, adolescents who perceived themselves as overweight had a mean difference in overall weight gain (delta BMI) that was $0.88 \mathrm{BMI}$ units larger than those who did not report self-perceived overweight. Additionally, adjusted for all relevant confounders, adolescents who reported self-perceived overweight had a 
higher gain of 0.66 BMI units than those, who did not report self-perceived overweight (Table 3 ). The difference between the two groups was significant $(P=0.011)$.

In relation to central adiposity using delta WC, the gain for the normal weight adolescents reporting self-perceived overweight was 3.46 centimetres more than those who did not reported self-perceived overweight, adjusted for all relevant confounders. The difference between the 2 groups was significant at $P<0.001$.

When repeating the linear regression analyses stratified for sex, the effect estimates seemed higher in girls than in boys (Delta BMI in girls B: 0.89 , CI: $0.3-1.5$ and in boys $B$ : -0.01 , CI: $-0.89-0.86)$. Delta WC in girls $B: 4.1$, CI: $2.0-6.2$ and in boys $B: 1.4$, CI: $-1.3-4.1)$. However, the linear regression models shown have not been stratified for sex because the interaction terms between self-perceived overweight and sex were not significant (delta BMI: $P=0.14$ and delta WC: $P=0.23$ ).

No statistical significant interactions were found between physical activity measured either at baseline or at follow-up level and self-perceived overweight in the determination of weight gain from adolescence to young adulthood.

\section{Discussion}

In this population based follow-up study normal weight adolescents who felt overweight at baseline had a larger weight gain, both measured as increase in BMI-units and waist circumference, than adolescents who perceived their weight about right. The associations remained significant after adjusting for potential confounding factors. Level of physical activity did not moderate this effect.

Defining overweight and obesity in adolescents is different from adults, as muscularity and sexual maturation [31] may vary at this age and consequently affect BMI. These aspects are, however, accounted for when defining normal weight as suggested by Cole et al. [21] In our study mean BMI was slightly lower in boys compared to girls; this may be due to earlier maturation of the girls. Differences in pubertal timing in adolescence may affect the perception of weight, when comparing one's own weight to peer's weight and could influence weight development. However, early pubertal timing in adolescents with normal body weight in Young-HUNT 1 has been found not to increase the risk of becoming overweight later [31].

In both sexes and in all age groups, mean BMI and mean weight at baseline were slightly higher and mean height slightly lower in those who reported self-perceived overweight compared to those who did not report this, as was the case in those who became overweight or obese at followup compared to those who did not. This could imply that a higher mean BMI might predict higher overall body adiposity in adulthood, as indicated by Singh et al. [32] and Reilly et al. [33], and we cannot totally ignore such an effect. However, the age adjusted differences did not reach statistically significance and in our study mean BMI in both genders and in nearly all age groups were as much as 2 to 3 BMI units beneath the cut-off level defining overweight, as
TABLE 3: Multiple linear regression models showing the effect estimates of the associations between perceived overweight in normal weight adolescents and their weight gain into young adulthood measured as overall adiposity (BMI) and central adiposity (WC). Adolescents with normal weight who reported psychological or physical dysfunctions at baseline and pregnancy at followup were excluded. ( $n$ : 1196).

\begin{tabular}{lccc}
\hline & $B$ & CI (95\%) & $P$ \\
\hline $\begin{array}{l}\text { Overall weight gain (BMI) } \\
\text { Self-perceived overweight }\end{array}$ & & & \\
$\quad$ Model I & 0.88 & $0.4-1.3$ & $<0.001$ \\
$\quad$ Model II & 0.66 & $0.1-1.2$ & 0.011 \\
\hline Central weight gain (WC) & & & \\
Self-perceived overweight & & & \\
$\quad$ Model I & 4.32 & $2.8-5.8$ & $<0.001$ \\
$\quad$ Model II & 3.46 & $1.8-5.1$ & $<0.001$ \\
\hline
\end{tabular}

Model I adjusted for sex, age, and age square.

Model II: additionally adjusted for physical activity at baseline and followup, sedentary behaviour, SES, social activities and eating habits (eating breakfast, vegetables or fruits).

$B$ : effect estimates, CI: confidence interval, $P$ : level of statistical significance.

proposed by Cole et al. [21] (varied from 20-23 BMI units corresponding to adult levels). Therefore, we believe that it is unlikely that these modest baseline differences would be responsible for our findings. Furthermore, employing weight gain as outcome we have tried to deal with the differences in baseline adiposity values as good as possible. In addition, we introduced the baseline values of BMI or WC in the respective regression models, but this did not change the results (data not shown). In the final results, we have chosen not to adjust for baseline BMI or WC, because this may also induce a bias [34].

Restricting the study sample to only normal weight adolescents may possibly have induced some selection bias. Because, if the exposure predicts baseline level of the outcome, conditioning on this baseline measure, that is, excluding low- or high-scoring individuals may induce spurious correlations between the exposure and change score [34]. However, since weight misperception may be present more strongly in the overweight and underweight adolescents $[12,35]$ and our objective was to investigate whether self-perceived overweight would affect weight gain in adolescents with normal weight [21]; our study population was strictly limited to girls and boys with a normal weight.

Weight development may be associated with socioeconomic inequalities [36], but adjusting for socioeconomic status based on vocational status at followup did not change any of the associations substantially.

Social activities were taken into account as possible confounders as suggested by previous studies [24, 37, 38]. We adjusted for physical activity at baseline in addition to physical activity at followup, as previous studies have documented that the current level of physical activity is more predictive of weight development than baseline physical activity level $[39,40]$. Introduction of any of the cofactors changed the association. 
6.1. Possible Pathways. Weight gain is caused by an imbalance between energy intake and expenditure. However, the development of weight may also be influenced by social factors as parental eating habits and SES, by psychological factors such as comfort eating, reward eating, and emotional eating, and of biological ones, for example, genetics. As Swinburn et al. [41] suggested, it is not only important to support individuals to counteract the effects of obesogenic environments, but the priority should be for policies to reverse the obesogenic nature of these environments.

The higher prevalence of self-perceived overweight among girls than boys in our study is in concordance with previous reports $[4,24]$. Overestimating peer weight norms may contribute to self-perception of overweight [24]. This may in itself be experienced as a kind of psychosocial pressure $[4,13,35]$, which again may have an impact specifically on abdominal adiposity [12]. Lynch et al. [42] suggested that unrealistic body size goals might be related to weight gain and proposed that, because of cultural focus on thinness, self-perception as overweight may lead to weight-related anxiety. They noted that obese adult women who saw themselves as obese lost weight, while those obese women whose ideal body size was normal weight gained more weight. Also among normal weight adult women and men did those who perceived themselves as slightly too large gain more weight. This supports our findings.

Our data indicate that as adults more boys (9\%) than girls $(8 \%)$ became overall obese expressed in BMI. When applying WC, however, substantially more girls (34\%) than boys (9\%) were defined as central obese at followup. This gender difference in WC is of such magnitude that an eventual adjustment of the thresholds for obesity classification, according to Katzmarzyk et al. [43], would not influence the results. A reason for such gender difference may be the larger media focus on looks directed towards girls than boys resulting in boys being more satisfied with their weight [8, 44], showing less slimming behaviour [45] and boys might consequently experience less psychosocial stress. According to Bangasser et al. [46], Yuan [4], and Bakker et al. [47], girls are more vulnerable to stress-related psychopathology. If girls are more prone to experience psychosocial pressure than boys, this may reflect the higher prevalence of girls with central obesity at followup as stress is shown to be associated with central obesity [12].

Adolescents seeing themselves as overweight may focus more on food and shift to unhealthy dietary behaviours resulting in weight gain [25]. Our data showed that eating behaviour (i.e., skipping breakfast) contributed significantly in the residual variation in the association between selfperceived overweight and becoming overweight and/or obese. This is in accordance with Mikkilä et al. [8] who found an association between eating behaviour and weight misperception.

The "dieting makes you fat" theory by Cannon and Einzig [48], and the study of Levin [49] on rodents supports the observation that overweight people who repeatedly try to lose weight have a tendency to become overweight again. Our study indicates that this theory also may be applicable in normal weight adolescents who feel overweight.
We investigated perceived pressure to slim by asking the normal weight adolescents: "Are you trying to slim" and defined perceived pressure to slim by combining the answers: "Yes" or "No, but I need to lose weight". The two concepts self-perceived overweight and perceived pressure to slim were highly correlated ( $R$ : 0.48 in girls and 0.34 in boys, $P<0.01$ ). The effect estimates of perceived pressure to slim on weight gain showed the same tendency as self-perceived overweight did (data not shown).

6.2. Implications and Further Research. Having normal weight and being satisfied with their weight are favourable factors for an adolescent. Weight perceptions are, however, often unrealistic. Girls, in particular, tend to consider themselves as overweight, even though they are not, which may lead to psychosocial stress and unhealthy weight control practices such as skipping meals.

The finding that more girls (34\%) than boys (9\%) became central obese brings up the question whether girls would be more vulnerable for future comorbidities as for instance cardiovascular diseases. This may be an important public health issue for policy makers. In developing school programs, policy makers should take the relationship between self-perceived overweight and development of overweight into account, while aiming at correcting the weight norms and consequently reduce the obesogenic effect of selfperceived overweight.

Because early intervention in the prevention of overweight is desirable and self-perceived overweight among normal weight adolescents seems to be a risk factor, health policy makers should implement these findings in future development of health interventions. More longitudinal studies are warranted to confirm our findings and explore possible pathways.

\section{Conclusion}

This study demonstrates that the adolescents, classified as normal weight, though perceiving themselves as overweight, have a larger weight gain into young adulthood than those who do not experience self-perceived overweight. Physical activity seemed not to moderate the effect of self-perceived overweight on this weight gain. Public health interventions aiming to reverse the obesogenic nature of the environment may benefit from focusing on healthy body shapes and the quality of the content and dissemination of the health messages.

\section{Conflict of Interests}

The authors declare that they have no conflict of interests.

\section{Acknowledgments}

The present study was supported by a grant from The Norwegian Research Council. The Nord-Trøndelag Health Study (HUNT) is a cooperation between the HUNT Research Center, Faculty of Medicine, Norwegian University 
of Science and Technology (NTNU), the Norwegian Institute for Public Health, and the Nord-Trøndelag County Council. The authors wish to thank Crystal Lee, Postdoctoral Research Fellow at the Boden Institute of Obesity, Nutrition and Exercise, University of Sydney and Imre Yanszki, Associate Professor at the Department of Public Health and General Practice, NTNU Norway for their help in the statistical part of the study.

\section{References}

[1] C. B. Ebbeling, D. B. Pawlak, and D. S. Ludwig, "Childhood obesity: public-health crisis, common sense cure," The Lancet, vol. 360, no. 9331, pp. 473-482, 2002.

[2] M. L. Butryn and T. A. Wadden, "Treatment of overweight in children and adolescents: does dieting increase the risk of eating disorders?" International Journal of Eating Disorders, vol. 37, no. 4, pp. 285-293, 2005.

[3] S. Lewis, S. L. Thomas, J. Hyde, D. Castle, R. W. Blood, and P. A. Komesaroff, "II don't eat a hamburger and large chips every day!' a qualitative study of the impact of public health messages about obesity on obese adults," BMC Public Health, vol. 10, article 309, 2010.

[4] A. S. V. Yuan, "Body perceptions, weight control behavior, and changes in adolescents' psychological well-being over time: a longitudinal examination of gender," Journal of Youth and Adolescence, vol. 39, no. 8, pp. 927-939, 2010.

[5] A. Myers and J. C. Rosen, "Obesity stigmatization and coping: relation to mental health symptoms, body image, and selfesteem," International Journal of Obesity, vol. 23, no. 3, pp. 221-230, 1999.

[6] R. F. Valois, K. J. Zullig, E. S. Huebner, and J. W. Drane, "Dieting behaviors, weight perceptions, and life satisfaction among public high school adolescents," Eating Disorders, vol. 11, no. 4, pp. 271-288, 2003.

[7] K. E. Friedman, S. K. Reichmann, P. R. Costanzo, and G. J. Musante, "Body image partially mediates the relationship between obesity and psychological distress," Obesity Research, vol. 10, no. 1, pp. 33-41, 2002.

[8] V. Mikkilä, M. Lahti-Koski, P. Pietinen, S. M. Virtanen, and M. Rimpelä, "Factors linked to obesity and body weight perception in adolescents," Duodecim, vol. 118, no. 9, pp. 921929, 2002.

[9] H. Sweeting, C. Wright, and H. Minnis, "Psychosocial correlates of adolescent obesity, "slimming down" and 'becoming obese," Journal of Adolescent Health, vol. 37, no. 5, p. 409, 2005.

[10] D. S. Kim, "Body image dissatisfaction as an important contributor to suicidal ideation in Korean adolescents: gender difference and mediation of parent and peer relationships," Journal of Psychosomatic Research, vol. 66, no. 4, pp. 297-303, 2009.

[11] W. Jansen, P. M. van de Looij-Jansen, E. J. de Wilde, and J. Brug, "Feeling fat rather than being fat may be associated with psychological well-being in young dutch adolescents," Journal of Adolescent Health, vol. 42, no. 2, pp. 128-136, 2008.

[12] P. Björntorp, "Do stress reactions cause abdominal obesity and comorbidities?" Obesity Reviews, vol. 2, no. 2, pp. 73-86, 2001.

[13] D. G. Byrne, S. C. Davenport, and J. Mazanov, "Profiles of adolescent stress: the development of the adolescent stress questionnaire (ASQ)," Journal of Adolescence, vol. 30, no. 3, pp. 393-416, 2007.

[14] P. B. Reagan and P. J. Salsberry, "Pathways to adolescent overweight: body mass index and height percentile change in childhood," International Journal of Pediatric Obesity, vol. 5, no. 1 , pp. 80-87, 2010.

[15] T. I. A. Sørensen, A. Rissanen, M. Korkeila, and J. Kaprio, "Intention to lose weight, weight changes, and 18-y mortality in overweight individuals without co-morbidities," PLoS Medicine, vol. 2, no. 6, Article ID e171, 2005.

[16] A. A. Mamun, S. Cramb, B. M. McDermott, M. O'Callaghan, J. M. Najman, and G. M. Williams, "Adolescents' perceived weight associated with depression in young adulthood: a longitudinal study," Obesity, vol. 15, no. 12, pp. 3097-3105, 2007.

[17] J. M. Perkins, H. W. Perkins, and D. W. Craig, "Peer weight norm misperception as a risk factor for being over and underweight among UK secondary school students," European Journal of Clinical Nutrition, vol. 64, no. 9, pp. 965-971, 2010.

[18] Statistical Yearbook of Norway 2009, Oslo, Norway, 2009.

[19] J. Holmen, K. Midthjell, Ø. Krüger et al., "The NordTrøndelag health study 1995-97 (HUNT2). Objectives, contents, methods and participation," Norsk Epidemiologi, vol. 13, pp. 19-32, 2003.

[20] S. Krokstad and S. Westin, "Health inequalities by socioeconomic status among men in the Nord-Trøndelag Health Study, Norway," Scandinavian Journal of Public Health, vol. 30, no. 2, pp. 113-124, 2002.

[21] T. J. Cole, M. C. Bellizzi, K. M. Flegal, and W. H. Dietz, "Establishing a standard definition for child overweight and obesity worldwide: international survey," British Medical Journal, vol. 320, no. 7244, pp. 1240-1243, 2000.

[22] V. Rangul, T. L. Holmen, N. Kurtze, K. Cuypers, and K. Midthjell, "Reliability and validity of two frequently used selfadministered physical activity questionnaires in adolescents," BMC Medical Research Methodology, vol. 8, article 47, 2008.

[23] A. Must and D. J. Tybor, "Physical activity and sedentary behavior: a review of longitudinal studies of weight and adiposity in youth," International Journal of Obesity, vol. 29, no. 2, pp. S84-S96, 2005.

[24] N. A. Christakis and J. H. Fowler, "The spread of obesity in a large social network over 32 years," The New England Journal of Medicine, vol. 357, no. 4, pp. 370-379, 2007.

[25] H. M. Niemeier, H. A. Raynor, E. E. Lloyd-Richardson, M. L. Rogers, and R. R. Wing, "Fast food consumption and breakfast skipping: predictors of weight Gain from adolescence to adulthood in a nationally representative sample," Journal of Adolescent Health, vol. 39, no. 6, pp. 842-849, 2006.

[26] WHO. Consultation on Obesity, Obesity: Preventing and Managing the Global Epidemic. Report of a WHO Consultation, WHO Technical Report Series Geneva, 2000.

[27] T. S. Han, E. M. van Leer, J. C. Seidell, and M. E. J. Lean, "Waist circumference action levels in the identification of cardiovascular risk factors: prevalence study in a random sample," British Medical Journal, vol. 311, no. 7017, pp. 14011405, 1995.

[28] M. E. Lean, T. S. Han, and C. E. Morrison, "Waist circumference as a measure for indicating need for weight management," British Medical Journal, vol. 311, no. 6998, pp. 158-161, 1995.

[29] N. Kurtze, V. Rangul, B. E. Hustvedt, and W. D. Flanders, "Reliability and validity of self-reported physical activity in the Nord-Trøndelag Health Study (HUNT 2)," European Journal of Epidemiology, vol. 22, no. 6, pp. 379-387, 2007.

[30] S. Krokstad, A. E. Kunst, and S. Westin, "Trends in health inequalities by educational level in a Norwegian total population study," Journal of Epidemiology and Community Health, vol. 56, no. 5, pp. 375-380, 2002. 
[31] G. H. Bratberg, T. I. L. Nilsen, T. L. Holmen, and L. J. Vatten, "Early sexual maturation, central adiposity and subsequent overweight in late adolescence. A four-year follow-up of 1605 adolescent Norwegian boys and girls: the young HUNT study," BMC Public Health, vol. 7, article 54, 2007.

[32] A. S. Singh, C. Mulder, J. W. R. Twisk, W. van Mechelen, and M. J. M. Chinapaw, "Tracking of childhood overweight into adulthood: a systematic review of the literature," Obesity Reviews, vol. 9, no. 5, pp. 474-488, 2008.

[33] J. J. Reilly, E. Methven, Z. C. McDowell et al., "Health consequences of obesity," Archives of Disease in Childhood, vol. 88, no. 9, pp. 748-752, 2003.

[34] M. M. Glymour, J. Weuve, L. F. Berkman, I. Kawachi, and J. M. Robins, "When is baseline adjustment useful in analyses of change? An example with education and cognitive change," American Journal of Epidemiology, vol. 162, no. 3, pp. 267-278, 2005.

[35] M. E. Eisenberg, D. Neumark-Sztainer, M. Story, and C. Perry, "The role of social norms and friends' influences on unhealthy weight-control behaviors among adolescent girls," Social Science and Medicine, vol. 60, no. 6, pp. 1165-1173, 2005.

[36] S. M. Nilsen, S. Krokstad, T. L. Holmen, and S. Westin, 'Adolescents' health-related dietary patterns by parental socio-economic position, the Nord-Trøndelag health study (HUNT)," European Journal of Public Health, vol. 20, no. 3, pp. 299-305, 2010.

[37] L. M. Koehly and A. Loscalzo, "Adolescent obesity and social networks.," Preventing Chronic Disease, vol. 6, no. 3, p. A99, 2009.

[38] H. R. Lajunen, A. Keski-Rahkonen, L. Pulkkinen, R. J. Rose, A. Rissanen, and J. Kaprio, "Leisure activity patterns and their associations with overweight: a prospective study among adolescents," Journal of Adolescence, vol. 32, no. 5, pp. 1089$1103,2009$.

[39] D. F. Williamson, J. Madans, R. F. Anda, J. C. Kleinman, H. S. Kahn, and T. Byers, "Recreational physical activity and tenyear weight change in a US national cohort," International Journal of Obesity and Related Metabolic Disorders, vol. 17, pp. 279-286, 1993.

[40] L. Petersen, P. Schnohr, and T. I. Sorensen, "Longitudinal study of the long-term relation between physical activity and obesity in adults," International Journal of Obesity and Related Metabolic Disorders, vol. 28, pp. 105-112, 2004.

[41] B. A. Swinburn, G. Sacks, K. D. Hall, K. McPherson, D. T. Finegood, M. L. Moodie et al., "The global obesity pandemic: shaped by global drivers and local environments," The Lancet, vol. 378, pp. 804-814, 2011.

[42] E. Lynch, K. Liu, G. S. Wei, B. Spring, C. Kiefe, and P. Greenland, "The relation between body size perception and change in body mass index over 13 years," American Journal of Epidemiology, vol. 169, no. 7, pp. 857-866, 2009.

[43] P. T. Katzmarzyk, G. A. Bray, F. L. Greenway et al., "EthnicSpecific BMI and waist circumference thresholds," Obesity, vol. 19, no. 6, pp. 1272-1278, 2011.

[44] M. A. Burke, F. W. Heiland, and C. M. Nadler, "From overweight to about right: evidence of a generational shift in body weight norms," Obesity, vol. 18, no. 6, pp. 1226-1234, 2010.

[45] R. M. Viner, M. M. Haines, S. J. C. Taylor, J. Head, R. Booy, and S. Stansfeld, "Body mass, weight control behaviours, weight perception and emotional well being in a multiethnic sample of early adolescents," International Journal of Obesity, vol. 30, no. 10, pp. 1514-1521, 2006.
[46] D. A. Bangasser, A. Curtis, B. A. S. Reyes et al., "Sex differences in corticotropin-releasing factor receptor signaling and trafficking: potential role in female vulnerability to stressrelated psychopathology," Molecular Psychiatry, vol. 15, no. 9, pp. 896-904, 2010.

[47] M. P. Bakker, J. Ormel, F. C. Verhulst, and A. J. Oldehinkel, "Peer stressors and gender differences in adolescents' mental health: the TRAILS study," Journal of Adolescent Health, vol. 46, no. 5, pp. 444-450, 2010.

[48] G. Cannon and H. Einzig, Eds., Dieting Makes you Fat, Century Publishing, London, UK, 1983.

[49] B. E. Levin, "Epigenetic influences on food intake and physical activity level: review of animal studies," Obesity, vol. 16, supplement 3, pp. S51-S54, 2008. 


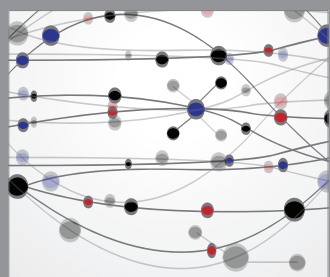

The Scientific World Journal
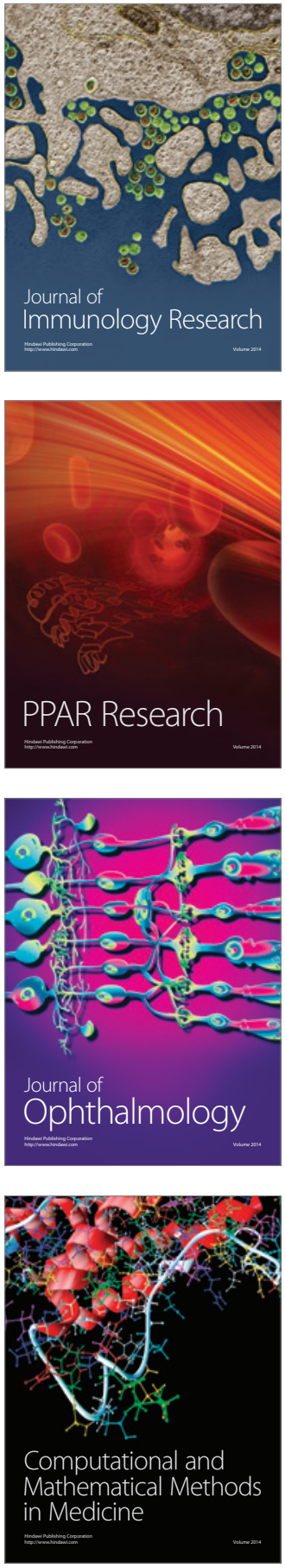

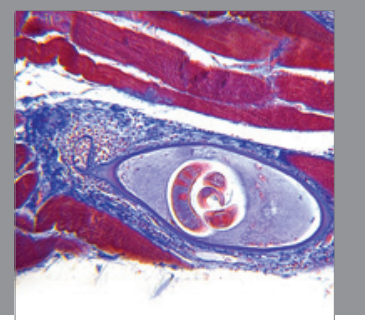

Gastroenterology

Research and Practice
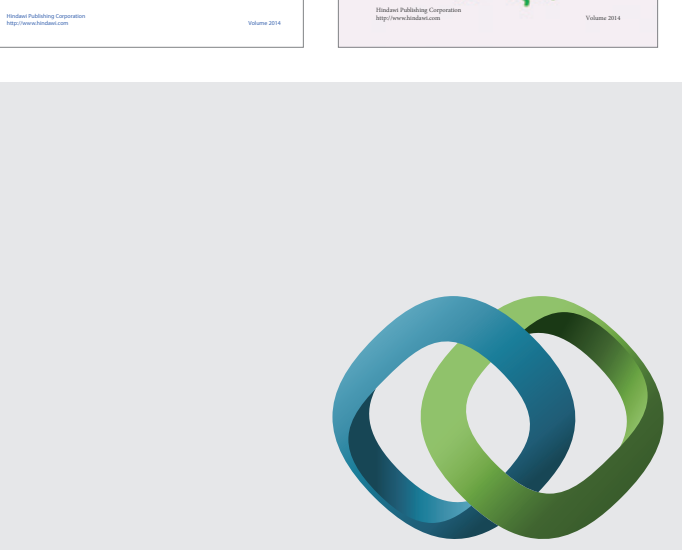

\section{Hindawi}

Submit your manuscripts at

http://www.hindawi.com
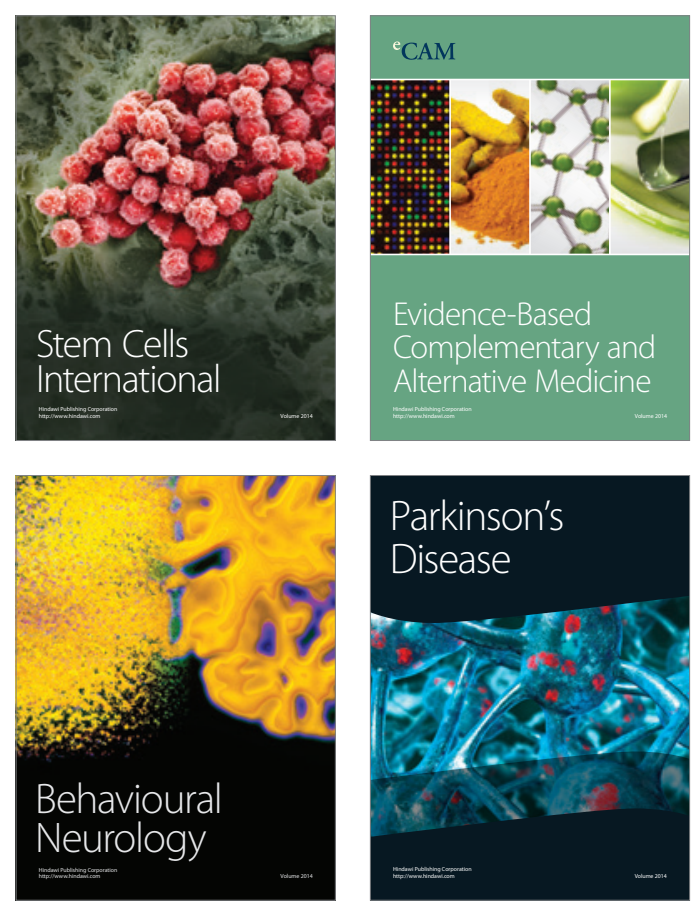

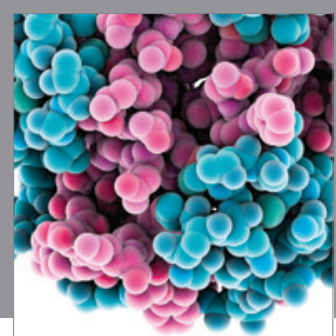

Journal of
Diabetes Research

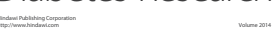

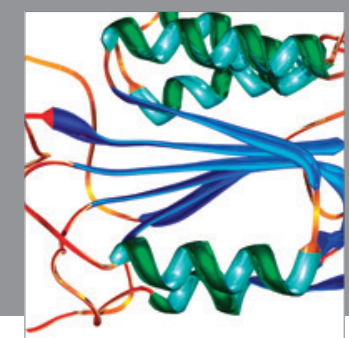

Disease Markers
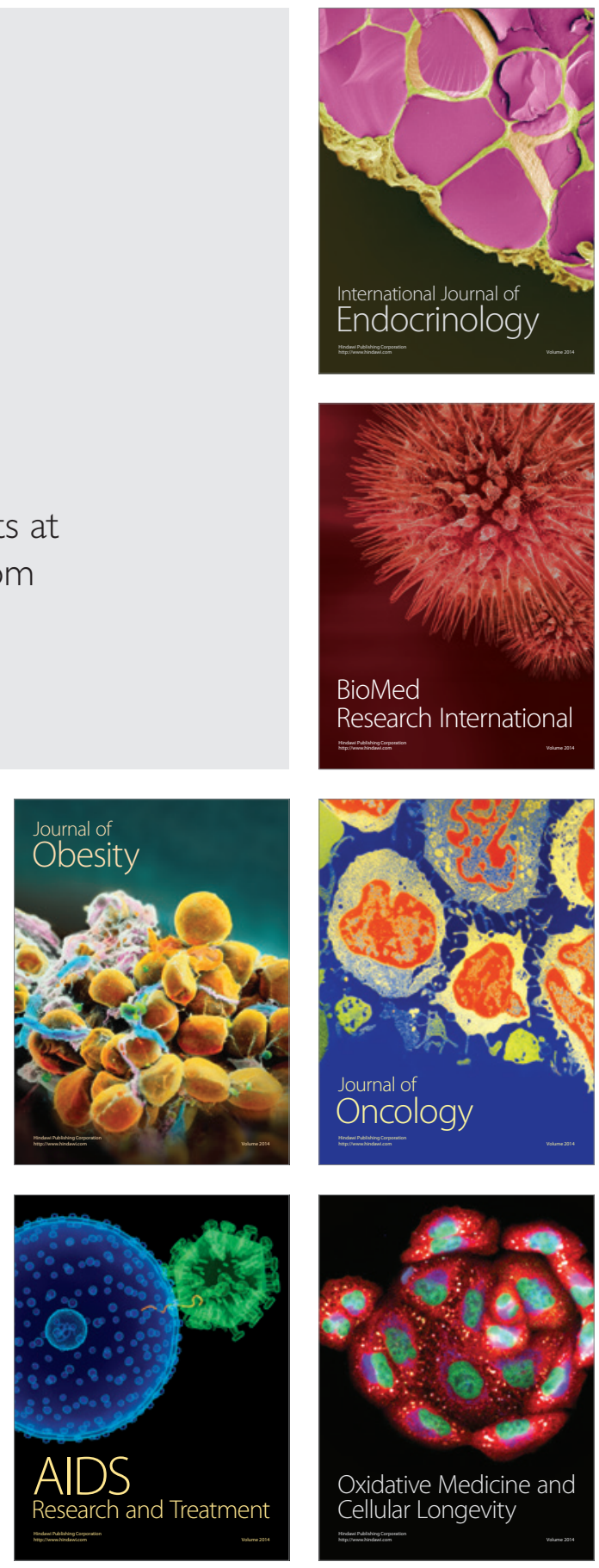